\title{
Investigation of Different Formulation Approaches to Enhance Oral Bioavailability of Paromomycin
}

\author{
M. J. S. K. PINJARI*, R. S. SOMANI AND R. M. GILHOTRA \\ Department of Research, School of Pharmacy, Suresh Gyanvihar University, Mahal, Jagatpura, Jaipur-302 017, India
}

Pinjari, et al.: Different Formulation Approach for Paromomycin

\begin{abstract}
Paromomycin, an aminoglycoside antibiotic, is used to treat visceral leishmaniasis as an intramuscular injection daily for 21 days since it has limited oral bioavailability. The objective of this investigation is to improve the oral bioavailability through formulation development for increased patient compliance and convenience. Comparative pharmacokinetic studies of intravenous and oral administration of paromomycin in mice to evaluate different formulation approaches to increase oral bioavailability were carried out. Following intravenous injection of $15 \mathrm{mg} / \mathrm{kg}$ to mice, paromomycin exhibited low plasma clearance $(8 \mathrm{ml} / \mathrm{min} / \mathrm{kg})$ with elimination half-life of $2.6 \mathrm{~h}$. Following oral administration of $500 \mathrm{mg} / \mathrm{kg} \mathrm{of} \mathrm{a}$ suspension formulation using carboxymethylcellulose to mice, referred to as formulation 1 , paromomycin showed very low or negligible oral bioavailability $(\% \mathrm{~F}=0.3)$. Different formulation approaches were made by employing a variety of FDA-approved novel excipients belonging to glycols, fatty acids, alcohols and surfactants alone and in various combinations. In vivo pharmacokinetic studies with these formulations demonstrated improved oral bioavailability of paromomycin in mice. Formulation approaches tested in the present research project were successful in improving the oral bioavailability of paromomycin from $0.3 \%$ to a maximum of $9 \%$. Overall, the increase in paromomycin bioavailability ranged 1-30 fold with different formulations compared to carboxymethylcellulose formulation. Formulation with $10 \%$ Gelucire $44 / 14$, $10 \%$ Solutol HS 15, 30\% propylene glycol and $50 \%$ normal saline showed higher bioavailability compared to formulation 1. This research provided evidence that improved bioavailability of paromomycin can be achieved through formulation development, which eventually could result in making the most tedious and painful intramuscular therapy redundant.
\end{abstract}

Key words: Paromomycin, visceral leishmaniasis, pharmacokinetics, formulation approach, permeability, metabolism, P-gp substrate

Visceral leishmaniasis (VL) is the most common vector borne parasitic disease caused by sand-fly. Out of 500000 cases detected in the world, most were from Asia, Sudan and Brazi ${ }^{[1]}$. Treatment options for VL are limited to antimonials, paromomycin, amphotericin $\mathrm{B}$, and miltefosine. The endemic region where antimonials failed with high drug resistance was recorded in India ${ }^{[2]}$.

Paromomycin was first developed in 1950s for local infections and was approved by Government of India in 2006 for the treatment of $\mathrm{VL}^{[3,4]}$. Although it was proved to be effective against VL way back in 1960s, only in 2006 it was approved by Government of India for the treatment of $\mathrm{VL}^{[1]}$. The major drawback with paromomycin is its negligible intestinal permeability with faecal excretion of $>99 \% 0^{[5,6]}$. Due to its limitation of no oral formulation availability

*Address for correspondence E-mail: jakirpinjari@yahoo.com due to poor bioavailability, the treatment is being done by intramuscular (IM) route of administration ${ }^{[7]}$. The treatment regime involves $21 \mathrm{~d}$ IM injection of paromomycin at the dose of $20 \mathrm{mg} / \mathrm{kg}$ and more than $95 \%$ cure rate can be obtained with 6 mo of treatment ${ }^{[7]}$. An additional challenge for the treatment in the rural areas like Bihar and other endemic regions has poor hospital infrastructure ${ }^{[8]}$. Therefore, an oral dosage form of paromomycin is necessary for patient amenability as an advantage over the available regime of IM injection.

This is an open access article distributed under the terms of the Creative Commons Attribution-NonCommercial-ShareAlike 3.0 License, which allows others to remix, tweak, and build upon the work non-commercially, as long as the author is credited and the new creations are licensed under the identical terms

Accepted 20 May 2017

Revised 20 January 2017

Received 11 August 2016

Indian J Pharm Sci 2017;79(4):568-575 
Not many research efforts are made pharmaceutical companies to improve paromomycin bioavailability, and as a result there is scarcity of data on paromomycin formulation and pharmacokinetics ${ }^{[9]}$. Hence, an attempt has been made in the current investigation to develop better oral formulations of paromomycin with the aim to improve oral bioavailability. Paromomycin is a substrate of efflux transporter, P-glycoprotein (P-gp) leading to its low oral bioavailability. Paromomycin is highly water soluble with a large molecular weight ${ }^{[10]}$. The oral bioavailability in human is almost zero or negligible following oral administration ${ }^{[5]}$. In view of these limitations, authors proposed that oral exposure of paromomycin could be enhanced using different formulation approaches either by increasing the membrane fluidity or by inhibiting efflux transporters. No studies have thus far reported oral pharmacokinetics of paromomycin in rodents. This would be the first preclinical report on the comparative pharmacokinetics of paromomycin using various formulations that are either permeability enhancers or P-gp inhibitors or their combinations to improve the oral bioavailability.

In the present investigation, various oral formulations were prepared using lipids, surfactants and co-surfactants excipients. In vivo experiments were performed in mice to determine the oral bioavailability of paromomycin from these formulations. Mouse was selected as a preclinical species for the pharmacokinetic studies since most of the in vivo efficacy models for $\mathrm{VL}$ are in mouse and the promising formulations can be tested orally to demonstrate pharmacokinetic and pharmacodynamics (PKPD) correlations.

\section{MATERIALS AND METHODS}

Paromomycin sulphate was purchased from Sigma, Germany. Labrasol was purchased from Gattefose, France. Menthol was purchased from Merck, India. Pluronic F-127 purchased from Sigma, USA. Sodium cholate was purchased from Sigma, New Zealand. Gelucire 44/14, Transcutol, Labrafil and Maisine were purchased from Gattefosse, France. Capmul MCM C8, Captex and Acconon MC 82 were obtained from Abitec Corp, Janesville, WI, USA. Cremophor EL, Tween 80 and propylene glycol were procured from Sigma Aldrich, St. Louis, MO, USA. Normal saline was procured from Baxter, India.

\section{Preparation of dose formulations:}

Formulation for intravenous (IV) dosing was prepared in $100 \%$ normal saline. Oral dosing formulations were prepared either in carboxymethyl cellulose (CMC, $0.5 \% \mathrm{w} / \mathrm{v}$ in RO water) or with different excipients. All formulations were prepared freshly on the day of dosing. Different categories of excipients were used including alcohols and glycols, surfactants, terpenes and acids and fatty alcohols. The excipients of other categories like $d$ - $\alpha$-tocopheryl polyethylene glycol 1000 succinate (TPGS) were also used. Various excipients used in the present research project along with the proportions used in formulations were tabulated in Tables 1 and 2 .

\section{Experimental animals:}

Animal studies were approved by the Institutional Animal Ethics Committee (IAEC) as per approval number FB-15-067 of Sai Life Sciences, Pune, India (an AAALAC accredited facility) and were in accordance with the Committee for the Purpose of Control and Supervision of Experiments on Animals (CPCSEA). Healthy male BALB/c mice (10-12 wold) weighing between 25 to $35 \mathrm{~g}$ were procured from Bharat Serum, Mumbai, India. Three mice were housed in each cage. Temperature and humidity were maintained at $22 \pm 3^{\circ}$ and $40-70 \%$, respectively with $12 \mathrm{~h}$ light and $12 \mathrm{~h}$ dark cycle. Temperature and humidity were recorded by auto-controlled data logger system. All the animals were provided laboratory rodent diet (Vetcare India Pvt. Ltd, Bengaluru, India). Reverse osmosis water treated with ultraviolet light was provided ad libitum to all the animals.

\section{Pharmacokinetic studies:}

Studies were performed in male BALB/c mice

\section{TABLE 1: LIST OF PERMEATION ENHANCERS}

Permeation enhancers

Alcohols and glycols

Surfactants

Essential oils and terpenes Sulfoxides and analogues Acids and fatty alcohols Others

\author{
Ethanol, propylene glycol, polyoxyethylene glycols, mannitol, Transcutol and Phospholipon $\mathrm{H}$ \\ Tween 80 , sodium lauryl sulphate, Pluronic F-127, Solutol HS-15, Cremophore EL and \\ polysorbate 20 and 60 \\ Menthol, oleic acid and lauricidine \\ Dimethyl sulfoxide, dimethyl acetamide and dimethyl formamide \\ Caprilic acid, Capmul MCM C8, Maisine, Captex, Gelucire, Acconon and Labrafil \\ Vitamin E-TPGS
}


(25-35 g). Paromomycin was administered IV at $15 \mathrm{mg} / \mathrm{kg}$ and at $500 \mathrm{mg} / \mathrm{kg}$ by oral gavage. There were total 12 groups and each group consisted of 9 mice. IV dose group (normal saline group) was received a single bolus dose administration through tail vein and other 11 groups were coded as oral formulation dose group from formulation 1-11 (Table 2). Mice were fasted $4 \mathrm{~h}$ prior to dose administration and food was provided $4 \mathrm{~h}$ post dose administration and water ad libitum during the entire period of experiments. Blood samples were collected by sparse sampling design ( $\mathrm{n}=3$ at each time point) at 0.08 (IV), 0.25, $0.05,1,2,4,8$ and $24 \mathrm{~h}$ (K2EDTA anticoagulant, $10 \mu \mathrm{l} / \mathrm{kg}$ ). Plasma was immediately harvested from the blood by centrifugation at $4000 \mathrm{rpm}$ for $10 \mathrm{~min}$ at $4 \pm 2^{\circ}$ and stored below $-70 \pm 10^{\circ}$ until bioanalysis. The dosing volumes were $5 \mathrm{ml} / \mathrm{kg}$ (IV) and $10 \mathrm{ml} / \mathrm{kg}$ (PO). The area under the concentration time curve (AUC), terminal half-life (T1/2), CLi.v, Vss was estimated by non-compartmental analysis module in Phoenix WinNonlin ${ }^{\circledR}$ (Version 6.3).

\section{Bioanalysis:}

Paromomycin and the internal standard (antipyrine) were analysed in in vivo samples using ultra-performance liquid chromatography (UPLC, Acquity, Waters, USA) mass spectrometry
(AB Sciex, USA). Positive-ion electron spray ionization mode was used with MRM transitions of 455.30/308.60 for paromomycin and 189.4/104.0 for antipyrine. Chromatographic separation was obtained using Acquity, BEH, HILIC column $(50 \times 2.1 \mathrm{~mm}$, $1.7 \mu \mathrm{m})$ maintained at $45^{\circ}$ with an injection volume of $5 \mu$ l.

In vivo plasma samples were extracted by using protein precipitation technique. A $25 \mu 1$ of plasma sample was added with $25 \mu 1$ of internal standard prepared in water (antipyrine, $500 \mathrm{ng} / \mathrm{ml}$ ) and vortexed. A $100 \mu \mathrm{l}$ of perchloric acid ( $10 \%$ prepared in water) was added and vortexed for $5 \mathrm{~min}$. Samples were centrifuged for $10 \mathrm{~min}$ at a speed of $4000 \mathrm{rpm}$ at $4^{\circ}$. Following centrifugation, $100 \mu 1$ of clear supernatant was transferred in 96 well plates and analysed using LC-MS/MS.

The lower limit of quantification (LLOQ) was $50.6 \mathrm{ng} / \mathrm{ml}$ and the calibration curve was linear over a 1000 -fold concentration range. All the study samples were processed along with calibration and quality control samples. An acceptance criterion of $\pm 15 \%$ for calibration curve and $\pm 20 \%$ for quality control samples was used.

\section{Statistical analysis:}

All values are expressed as mean \pm standard error of mean (SEM). Data were analysed for statistically

TABLE 2: COMPOSITIONS OF DIFFERENT EXCIPIENTS USEDIN ORAL FORMULATIONS OF PAROMOMYCIN USED IN MOUSE PK STUDIES

\begin{tabular}{|c|c|c|c|c|c|c|c|c|c|c|c|}
\hline \multirow{3}{*}{ Excipient } & \multicolumn{11}{|c|}{ Percent in normal saline } \\
\hline & \multicolumn{11}{|c|}{$\begin{array}{l}\text { Formulation } \\
\end{array}$} \\
\hline & 1 & 2 & 3 & 4 & 5 & 6 & 7 & 8 & 9 & 10 & 11 \\
\hline Carboxy methylcellulose & 0.5 & & & & & & & & & & \\
\hline Menthol & & 5 & & & 5 & & & & & & \\
\hline Pluronic F-127 & & 10 & & & & & & & & & \\
\hline Sodium cholate & & 10 & & & & & & & & & \\
\hline Tween 80 & & & 20 & & & 10 & & 20 & & & \\
\hline Sodium lauryl sulphate & & & 10 & & & & & & & & \\
\hline Phospholipon H & & & 20 & & & & & & & & \\
\hline Gelucire 44/14 & & & & 5 & & & 10 & 20 & 15 & & \\
\hline Capmul MCM C8 & & & & 5 & 10 & & & & & & 20 \\
\hline Cremophor EL & & & & & 10 & & & & & & 15 \\
\hline Captex & & & & & & 10 & & & & 35 & \\
\hline Transcutol & & & & & & 5 & & 20 & & & 20 \\
\hline Solutol HS-15 & & & & & & & 10 & & & 30 & \\
\hline Propylene glycol & & & & & & & 30 & & 30 & 20 & \\
\hline Acconon MC8 & & & & & & & & & 15 & & \\
\hline Labrafil & & & & & & & & & 20 & & \\
\hline Maisine & & & & & & & & & & 15 & 15 \\
\hline
\end{tabular}


significant differences using analysis of variance (ANOVA) followed by the two-sided unpaired Student's t-test. Differences were considered to be significant at a level of $\mathrm{P}<0.05$.

\section{RESULTS AND DISCUSSION}

After IV dose administration, paromomycin showed low plasma clearance $(8 \mathrm{ml} / \mathrm{min} / \mathrm{kg})$ in mice (CL less than $10 \%$ of normal hepatic blood flow) with elimination half-life of $2.6 \mathrm{~h}$. Compound exhibited high volume of distribution steady state $(>0.71 / \mathrm{kg}$, Table 3 ; fig. 1$)$. After a single oral dose administration of paromomycin with CMC formulation, it showed multiexponential disposition with a very low oral bioavailability $(0.3 \%)$. Oral exposures (AUC) of different paromomycin formulations (formulation 2 to 8 and 11) showed statistically significant improvement compared to $0.5 \% \mathrm{CMC}$ formulation of paromomycin (Table3). Formulation9and10didn'tshowimprovement in oral exposure of paromomycin. The maximum exposure observed was for formulation 7 , which was 30-fold higher than formulation 1 (fig. 2A, Table 4). Similar trend of increase in $\mathrm{C}_{\max }$ was also observed with different formulation approaches compared to CMC formulation. A maximum of $12.62 \mu \mathrm{g} / \mathrm{ml}$ of $\mathrm{C}_{\max }$ was observed with formulation 7 compared to CMC formulation. The mean concentration-time profiles for various formulations were depicted in fig. 2 .

Paromomycin is a large molecule with good water solubility and limited oral bioavailability due to its absorption limitation and/or substrate to efflux transporter(s). In view of this, selection of excipients

\begin{tabular}{|c|c|c|c|c|c|c|c|c|}
\hline Formulation no. & Route & $\begin{array}{l}T_{\max } \\
\text { (h) }\end{array}$ & $\begin{array}{l}C_{0} / C_{\max } \\
(\mu \mathrm{g} / \mathrm{ml})\end{array}$ & $\begin{array}{c}\mathrm{AUC}_{\text {last }} \\
(\mathrm{h} \times \mu \mathrm{g} / \mathrm{ml})\end{array}$ & $\begin{array}{l}T_{1 / 2} \\
\text { (h) }\end{array}$ & $\mathrm{CL}(\mathrm{ml} / \mathrm{min} / \mathrm{kg})$ & $\begin{array}{c}V_{\mathrm{ss}} \\
(\mathrm{l} / \mathrm{kg})\end{array}$ & $\% \mathrm{~F}^{\mathrm{b}}$ \\
\hline Normal saline & IV & - & 16.27 & 30.63 & 2.60 & 8.16 & 1.84 & - \\
\hline 1 & $\mathrm{PO}$ & 1.00 & 0.69 & 3.43 & - & - & - & 0.3 \\
\hline 2 & $\mathrm{PO}$ & 0.5 & 5.23 & 26.85 & - & - & - & 2.63 \\
\hline 3 & PO & 0.5 & 11.13 & 67.26 & - & - & - & 6.59 \\
\hline 4 & PO & 0.5 & 6.24 & 47.03 & - & - & - & 4.61 \\
\hline 5 & PO & 0.5 & 9.95 & 57.94 & - & - & - & 5.68 \\
\hline 6 & $\mathrm{PO}$ & 1.0 & 5.02 & 31.24 & - & - & - & 3.06 \\
\hline 7 & $\mathrm{PO}$ & 1.0 & 12.62 & 90.77 & - & - & - & 8.90 \\
\hline 8 & PO & 0.5 & 4.62 & 31.64 & - & - & - & 3.10 \\
\hline 9 & PO & 0.3 & 1.04 & 2.89 & - & - & - & 0.28 \\
\hline 10 & PO & 0.5 & 2.05 & 8.92 & - & - & - & 0.87 \\
\hline 11 & $\mathrm{PO}$ & 1.0 & 5.38 & 44.92 & - & - & - & 4.40 \\
\hline
\end{tabular}

In male BALB/C mice $(n=3) . C_{0}$; extrapolated concentration on $y$-axis for IV data

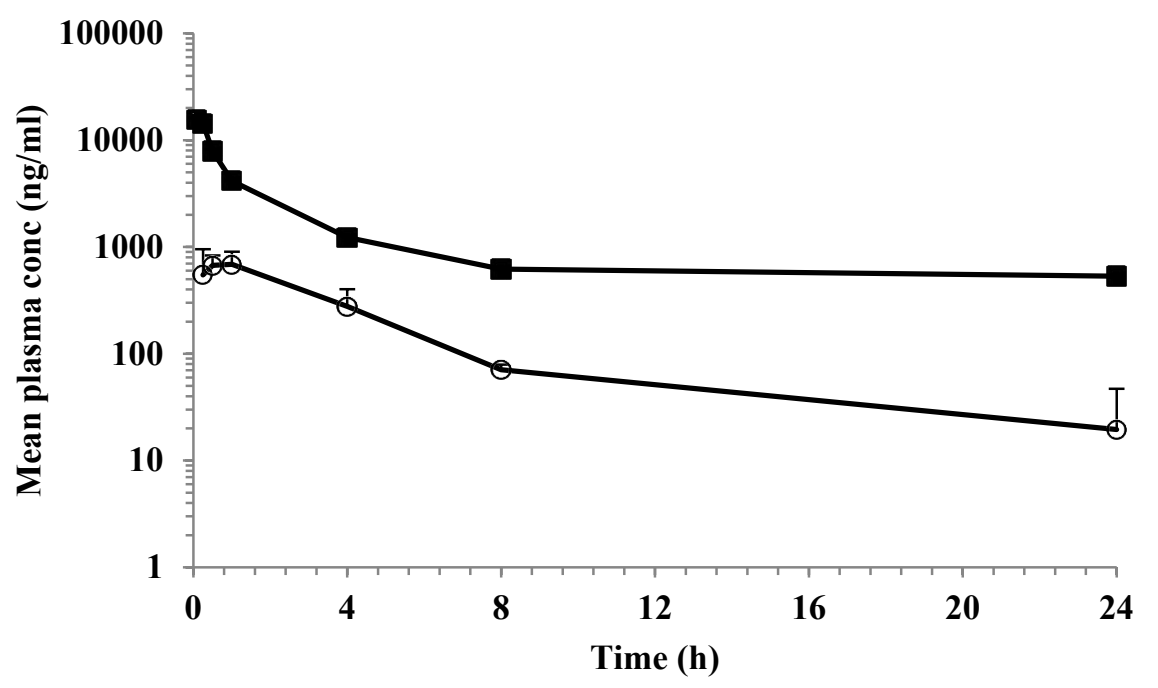

Fig. 1: Mean plasma concentration-time profiles of paromomycin 
was based on their effect on intestinal membrane or efflux transporter(s) or both. The excipient selection strategy covered maximum categories like alcohols and glycols: Phospholipon $\mathrm{H}$ and Transcutol; surfactants: Tween 80, Cremophore EL, Pluronic F-127, Solutol HS-15; terpenes: menthol; acids and fatty acids: Capmul, MCM C8, Maisine, Captex, Gelucire 44/14, Acconon and Labrafil.

The fatty alcohols used are medium chain fatty acids including capric acid (C10), lauric acid (C12) and long chain fatty acids, such as oleic acid fatty acids have been shown to increase the permeability of a series of hydrophilic drugs by dilating the tight junction and/or changing the cytoskeleton of the intestinal epithelial cells without prominent cytotoxicity. The main advantage of these excipients is the ease of integrating into the conventional oral dosage forms without the need for difficult or costly formulation technique, which is an advantage of providing cost effective

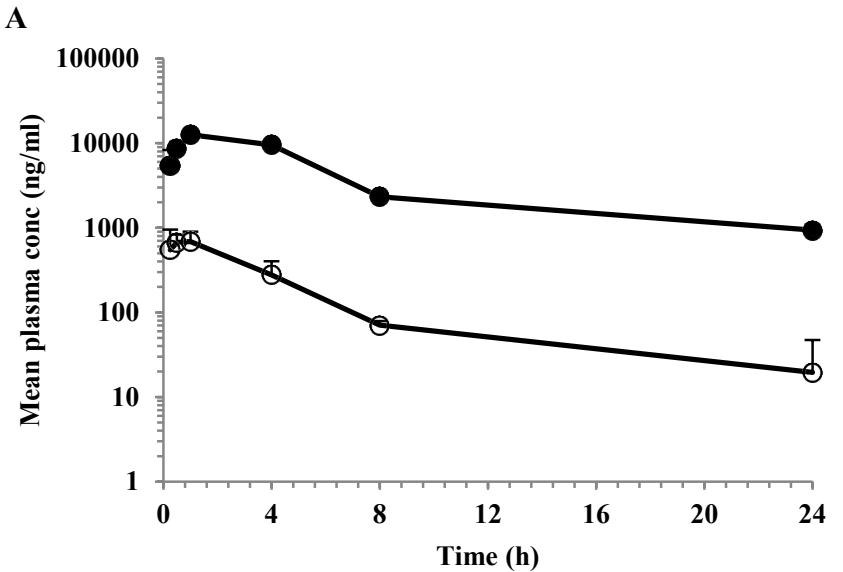

C

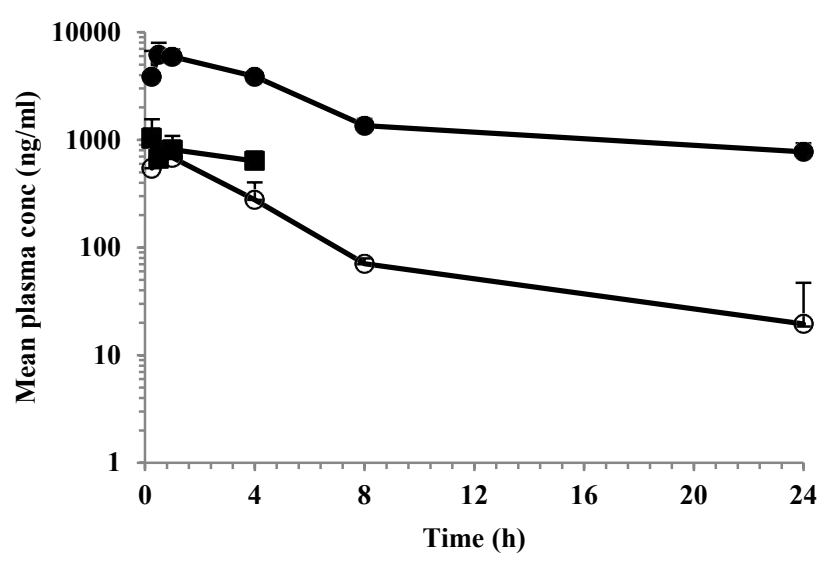

formulation apart from improved bioavailability ${ }^{[11]}$.

Terpenes are biosynthetically derived isoprene units, which increase the permeability of compounds by dilating the intestinal epithelium ${ }^{[12]}$. Glycols like phospholipon $\mathrm{H}$ is a lipoid characterized by natural and hydrogenated lecithin fractions and phospholipids that would enhance the absorption by changing the intestinal membrane fluidity ${ }^{[13]}$. The excipients like alcohols and glycols, fatty alcohols, surfactants and Solutol increase the permeability by increasing the membrane fluidity and/or disrupting the membrane structure ${ }^{[14-17]}$.

After IV dose administration, paromomycin exhibited low plasma clearance $(8 \mathrm{ml} / \mathrm{min} / \mathrm{kg})$ and moderate volume of distribution (1.84 $1 / \mathrm{kg})$ suggesting extravascular distribution. Paromomycin showed negligibleoralbioavailability $(0.3 \%)$ whenadministered in a CMC formulation. Our research data and study outcomes are in agreement with the study reported

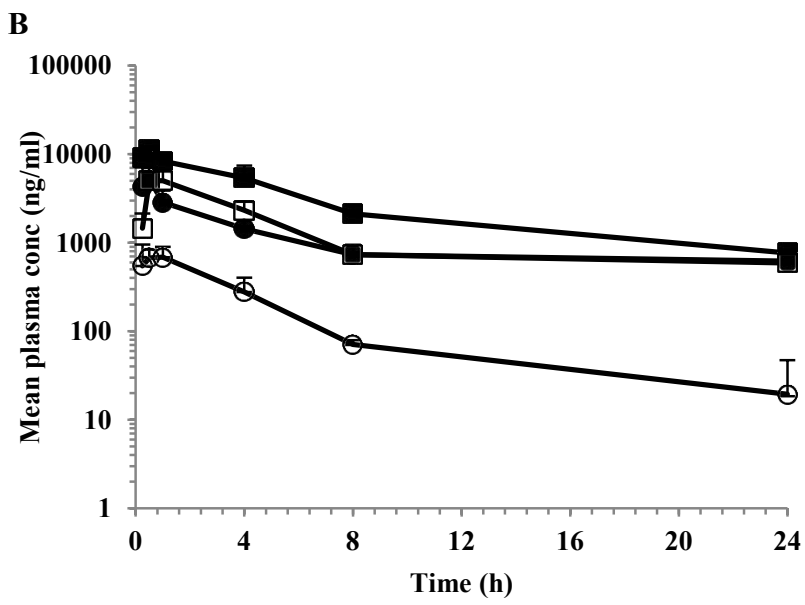

D

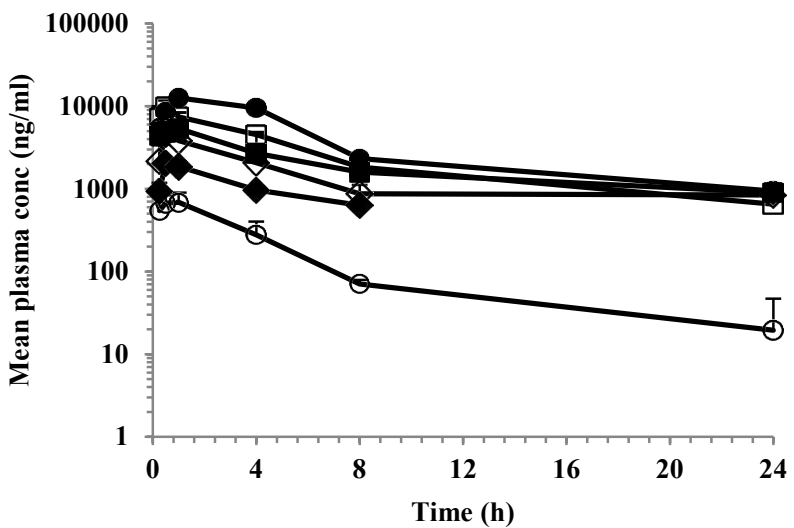

Fig. 2: Mean plasma concentration-time profiles of paromomycin after $P O$ dose $(500 \mathrm{mg} / \mathrm{kg})$

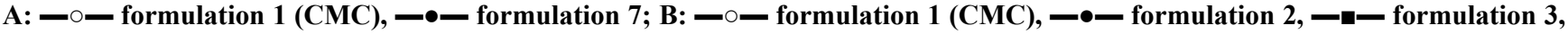

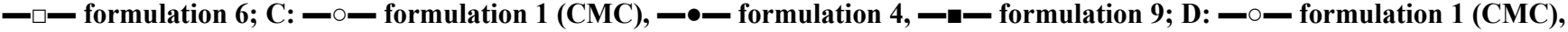

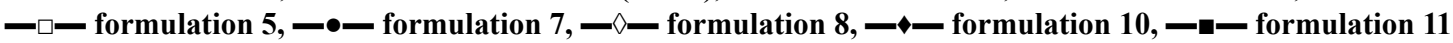


by Bissuel et al., where the absence of paromomycin in plasma after oral dose was attributed to absorption limitation ${ }^{[5]}$. This could be due to permeability limitation as it is a large molecule with a molecular weight of $615 \mathrm{Da}$ and a P-gp substrate. Considering large molecular weight, paromomycin could not be permeating through the intestinal tract and it being a P-gp substrate whatever permeated compound could be effluxed into the intestinal tract ${ }^{[18]}$. The present study was hypothesized that the absorption can be enhanced either by increasing the membrane fluidity and/or by inhibiting the efflux transporters. Hence to improve the oral bioavailability, the excipient that enhances the permeability and inhibit the P-gp efflux were employed in the formulation vehicle. The excipients used were belongs to different categories of permeation enhancers like glycols, surfactants, terpenes, fatty alcohols and others like TPGS. Glycols used were propylene glycol, Phospholipon $\mathrm{H}$ and transcutol and were reported to increase the permeability by changing the fluidity of intestinal membrane ${ }^{[19]}$. It was also reported that glycols increased the permeability by inhibiting the P-gp efflux transporter ${ }^{[19]}$. The use of $30 \%$ of propylene glycol in the present study showed much greater exposure than the reported value, which could be due to increasing the permeability in GI tract. Surfactants like sodium lauryl sulphate, Tween 80 and Cremophor EL were used at $\geq 10 \%$ and were reported to inhibit P-gp and SLS by increasing the fluidity of intestinal membrane resulting in increase in the plasma exposure ${ }^{[20]}$. Cremophor EL was also reported to increase the permeability by disrupting the intestinal barrier ${ }^{[21]}$. Terpenes like menthol were shown to increase the permeability either by increasing the fluidity or by disruption of tight junctions of intestinal membrane ${ }^{[22]}$. Fatty alcohols like Gelucire 44/14, Capmul MCM C8, Captex, Acconon, Labrafil and Maisine were shown to increase the permeability by disrupting the intestinal barrier $^{[22-24]}$. Solutol HS-15, a non-ionic surfactant was reported to increase the permeability by disrupting the membrane structure and/or increasing the membrane fluidity ${ }^{[25]}$. Peltier et al. also proved that Solutol HS-15 increased the plasma exposure of paclitaxel by inhibition of $\mathrm{P}-\mathrm{gp}^{[26]}$. Paromomycin prepared with different combinations of excipients either P-gp inhibitors and membrane disruptors or both, showed increase in the oral bioavailability compared to CMC formulation. All the formulation tested showed an increase in 9 to 30 fold oral bioavailability compared to $\mathrm{CMC}$ formulation $(0.3 \%)$ except the formulation 8 and 9. Amongst all the tested formulations, the formulation 7 showed highest bioavailability (8.9\%) for paromomycin. Formulation 7 consisted of Gelucire 44/14, Solutol HS-15 and propylene glycol, which increased the intestinal membrane fluidity/disrupt the membrane or inhibit the P-gp transporter. Overall, the increase in bioavailability across the tested formulation ranged 1-30 folds higher than the CMC formulation $(0.3 \%$; formulation 1$)$. The data was depicted in Table 4. Comparison of bioavailability with different formulations was depicted in fig. 3. In specific, as per the literature the increase in bioavailability could be due to increase in the intestinal membrane fluidity/ disrupt the membrane by Gelucire 44/14 and by both increase in intestinal membrane fluidity/disrupt the membrane or inhibition of the P-gp efflux transporter by Solutol and propylene glycol.

Interestingly, paromomycin being a substrate for efflux transporter and having a permeability limitation, bioavailability can be increased by adopting an alternative formulation approach, which was evident in present research. The compounds, which fall in negligible permeability and no oral bioavailability like paromomycin and other drugs can be used to increase the oral bioavailability by efficient utilization of excipients that can increase intestinal membrane fluidity, permeability and or P-gp inhibitor. Our hypothesis of increasing the permeability of paromomycin by incorporating the novel formulation excipients has proved to improve the oral bioavailability.

The present study provides first time detailed pharmacokinetic experiments that showed the improvement of oral exposure of paromomycin using different excipients (formulation based approaches) in mice. The formulation additives, i.e. the permeation enhancers, and/or P-gp inhibitors were well-tolerated

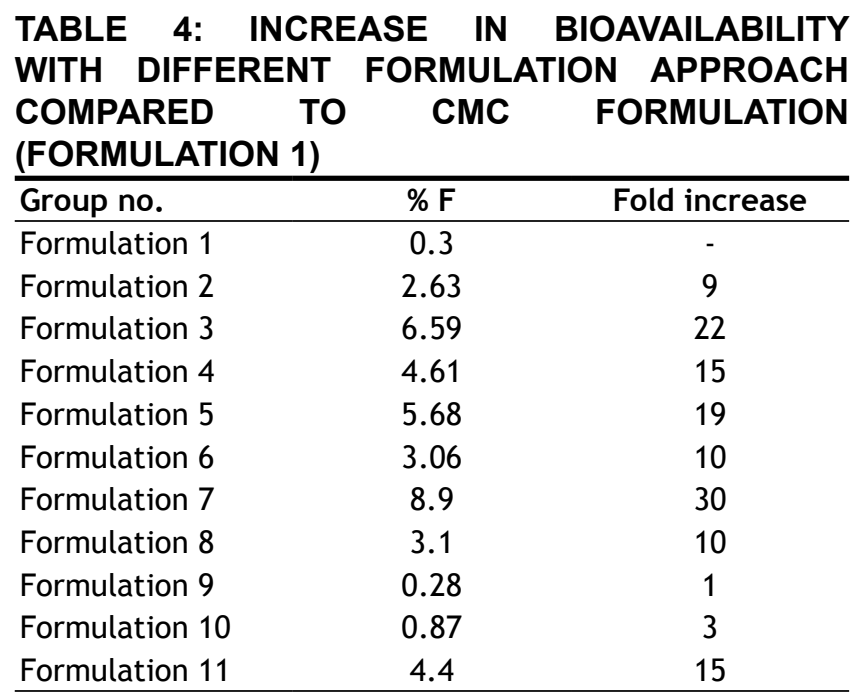




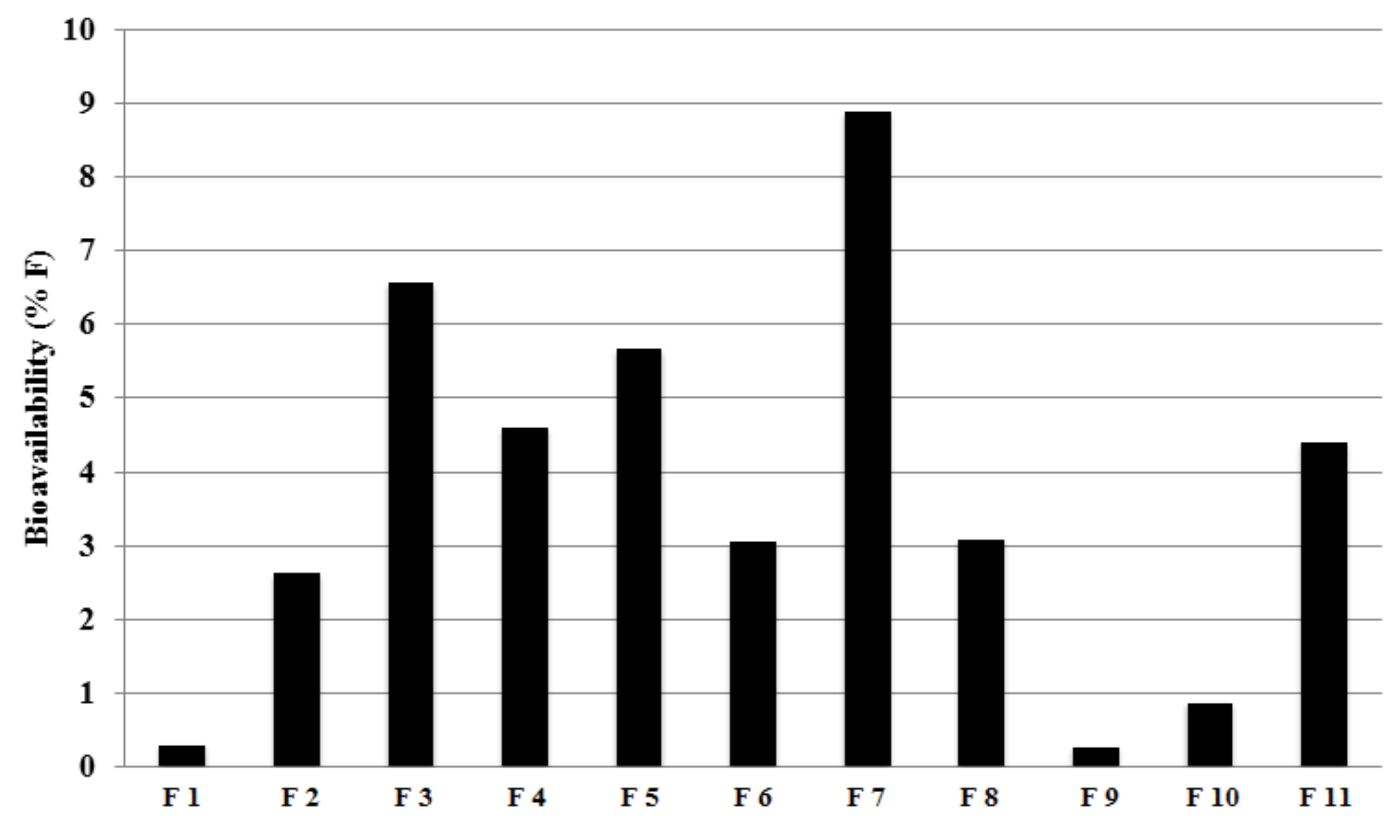

Fig. 3: Comparison of bioavailability of different oral formulations of paromomycin after PO dose $(500 \mathrm{mg} / \mathrm{kg})$

in mice at the administered doses in single dose IV and oral pharmacokinetic studies. The highest oral relative bioavailability of paromomycin was observed in formulation 7, which was significantly high compared to $\mathrm{CMC}$ formulation 1 . This evaluation provide evidence that paromomycin can be administered orally, which in turn help patient compliant. The outcome of this research is important for treatment compliance of paromomycin and further clinical studies required in future to establish our findings in clinic.

\section{Conflict of interest:}

The authors declare no conflict of interest.

\section{Financial support and sponsorship:}

Nil.

\section{REFERENCES}

1. Sundar S, Jha TK, Thakur CP, Sinha PK, Bhattacharya SK. Injectable paromomycin for visceral leishmaniasis in India. $\mathrm{N}$ Engl J Med 2007;356:2571-81.

2. Sundar S, More DK, Singh MK, Singh VP, Sharma S, Makharia A, et al. Failure of pentavalent antimony in visceral leishmaniasis in India: report from the center of the Indian epidemic. Clin Infect Dis 2000;31:1104-7.

3. Khan W, Kumar N. Characterization, thermal stability studies, and analytical method development of Paromomycin for formulation development. Drug Test Anal 2011;3:363-72.

4. Wiwanitkit V. Interest in paromomycin for the treatment of visceral leishmaniasis (kala-azar). Ther Clin Risk Manag 2012;8:323-8.

5. Bissuel F, Cotte L, de Montclos M, Rabodonirina M, Trepo C. Absence of systemic absorption of oral paromomycin during long-term, high-dose treatment for cryptosporidiosis in AIDS. J Infect Dis 1994;170:749-50.

6. Iwaki S, Honke K, Nishida N, Taniguchi N. The absorption, excretion and influence on bowel flora of oral paromomycin sulfate (author's transl). Jpn J Antibiot 1981;34:1078-81.

7. Moore EM, Lockwood DN. Treatment of visceral leishmaniasis. J Glob Infect Dis 2010;2:151-8.

8. Musa AM, Younis B, Fadlalla A, Royce C, Balasegaram M, Wasunna M, et al. Paromomycin for the treatment of visceral leishmaniasis in Sudan: a randomized, open-label, dosefinding study. PLoS Negl Trop Dis 2010;4:e855.

9. Mondal D, Singh SP, Kumar N, Joshi A, Sundar S, Das P, et al. Visceral leishmaniasis elimination programme in India, Bangladesh, and Nepal: reshaping the case finding/case management strategy. PLoS Negl Trop Dis 2009;3:e355.

10. Van Bocxlaer K, Yardley V, Murdan S, Croft SL. Drug permeation and barrier damage in Leishmania-infected mouse skin. J Antimicrob Chemother 2016;71:1578-85.

11. Shaikh MS I, Nikita D. Derle, Bhamber R. Permeability enhancement techniques for poorly permeable drugs: a review. J Applied Pharm Sci 2012;6:34-9.

12. Williams AC, Barry BW. Terpenes and the lipid-proteinpartitioning theory of skin penetration enhancement. Pharm Res 1991;8:17-24.

13. Indira TK, Lakshmi PK, Balasubramaniam J, Rajesh YV. Enhancement of bioavailability of fenofibrate with alpha tocopherol and phospholipids as solubilizers. J Bioequiv Availab 2012;S14:006.

14. Gelderblom H, Verweij J, Nooter K, Sparreboom A. Cremophor EL: the drawbacks and advantages of vehicle selection for drug formulation. Eur J Cancer 2001;37:1590-8.

15. Shono Y, Nishihara H, Matsuda Y, Furukawa S, Okada $\mathrm{N}$, Fujita $\mathrm{T}$, et al. Modulation of intestinal P-glycoprotein function by Cremophor EL and other surfactants by an in vitro diffusion chamber method using the isolated rat intestinal membranes. J Pharm Sci 2004;93:877-85.

16. Thakkar HP, Desai JL. Influence of excipients on drug 
absorption via modulation of intestinal transporters activity. Asian J Pharm 2015;9:69-82.

17. Takahashi K, Tamagawa S, Katagi T, Yoshitomi H, Kamada A, Rytting $\mathrm{JH}$, et al. In vitro transport of sodium diclofenac across rat abdominal skin: effect of selection of oleaginous component and the addition of alcohols to the vehicle. Chem Pharm Bull 1991;39:154-8.

18. Boddu SP, Yamsani MR, Potharaju S, Veeraraghavan S, Rajak S, Kuma SV, et al. Influence of grapefruit juice on the pharmacokinetics of diltiazem in Wistar rats upon single and multiple dosage regimens. Pharmazie 2009;64:525-31.

19. Aungst BJ. Intestinal permeation enhancers. J Pharm Sci 2000;89:429-42.

20. Bansal T, Akhtar N, Jaggi M, Khar RK, Talegaonkar S. Novel formulation approaches for optimising delivery of anticancer drugs based on P-glycoprotein modulation. Drug Discov Today 2009;14:1067-74.

21. Shono Y, Nishihara H, Matsuda Y, Furukawa S, Okada $\mathrm{N}$, Fujita $\mathrm{T}$, et al. Modulation of intestinal P-glycoprotein function by Cremophor EL and other surfactants by an in vitro diffusion chamber method using the isolated rat intestinal membranes. J Pharm Sci 2004;93:877-85.

22. Shen Q, Li X, Li W, Zhao X. Enhanced intestinal absorption of daidzein by borneol/menthol eutectic mixture and microemulsion. AAPS PharmSciTech 2011;12:1044-9.

23. Lerner A, Matthias T. Changes in intestinal tight junction permeability associated with industrial food additives explain the rising incidence of autoimmune disease. Auto Immun Rev 2015;14:479-89.

24. Pramod K, PeeyushK, RajeevK, NitishK, Rakesh K. An overview of lipid based formulation for oral drug delivery. Drug Inv Today 2010;2:390-5.

25. Wilson CG, Mahony BO. The behavior of fats and oils in the upper G. I. tract. Bull Tech Gattefosse 1997;90:13-8.

26. Shubber S, Vllasaliu D, Rauch C, Jordan F, Illum L, Stolnik S. Mechanism of mucosal permeability enhancement of CriticalSorb(R) (Solutol(R) HS15) investigated in vitro in cell cultures. Pharm Res 2015;32:516-27.

27. Peltier S, Oger JM, Lagarce F, Couet W, Benoit JP. Enhanced oral paclitaxel bioavailability after administration of paclitaxelloaded lipid nanocapsules. Pharm Res 2006;23:1243-50. 